\title{
A fuzzy stochastic multi-criteria model for the selection of urban pervious pavements
}

Daniel Jato-Espino, Jorge Rodriguez-Hernandez*, Valerio Carlos Andrés-Valeri, Francisco Ballester-Muñoz

GITECO Research Group, Civil Engineering School, Universidad de Cantabria, 39005 Santander, Spain

E-mail addresses: jatod@unican.es (D. Jato-Espino), rodrighj@unican.es (J. Rodriguez-

Hernandez), andresv@unican.es (V. C. Andrés-Valeri), francisco.ballester@unican.es (F. Ballester-Muñoz).

* Corresponding author. Tel.: +34 942201550; fax: +34 942201703.

\section{ABSTRACT}

Multi-criteria decision making methods (MCDM) have been widely used throughout the last years to assist project contractors in selection processes related to the construction field. Sustainable urban drainage systems (SUDS) are an especially suitable discipline to implement these techniques, since they involve important impacts on each branch of sustainability: economy, environment and society. Considering that pervious pavements constitute an efficient solution to manage urban stormwater runoff as a source control system, this paper presents a multi-criteria approach based on the Integrated Value Model for Sustainable Assessments (MIVES) method to facilitate their proper selection. Given the lack of accurate information to shape the behaviour of the alternatives regarding some of the criteria defining the decision-making environment, a series of variables are modelled by executing stochastic simulations based on the Monte Carlo methods. Additionally, a group of ten experts from various sectors related to water management was requested to provide their opinions about the importance of the set of selected criteria, according to the comparison levels of the Analytic Hierarchy Process (AHP). These judgments are converted into triangular fuzzy numbers, in order to capture the vagueness that human attitude entails when making judgments. A case of study in which the three major types of pervious pavements (Porous Asphalt, Porous 
Concrete and Interlocking Concrete Pavers) are evaluated is presented to demonstrate the potential of the model.

\section{KEYWORDS}

Pervious pavements; Multi-criteria decision making; MIVES; Monte Carlo methods; AHP; Fuzzy sets

\section{Introduction}

Sustainable urban drainage systems (SUDS) constitute a series of disciplines and techniques aimed to deal with several phenomena related to water management which impoverish both the state and quality of urban goods and services, like diffuse pollution, localized floods or loss of biodiversity (Fresno et al., 2005; Castro-Fresno et al., 2013). These systems, also known as Stormwater Best Management Practices (BMPs), have been classified in a considerably wide range of manners throughout the last years, according to different considerations and criteria. Some of them propose a division depending on the point where they are implemented, thus appearing source control as one of the most effective measures for treating runoff. Pervious pavements are in turn one of the preferred solutions within this group, due to the synergistic action of their component pervious layers, which enables them to adequately manage runoff at its earliest condition (Pratt et al., 2002). Such layers usually consist of the following, from top to bottom: (1) a surface, (2) a base layer, (3) a geotextile, (4) a subbase and (5) another geotextile or an impervious geomembrane which lies on the existent subgrade.

These combinations of multilayered structures confer different properties to the pavement, raising doubts and misgivings when choosing among them for its implementation in a certain project. Since this process is no more than a decisionmaking problem, in which a set of alternatives (pervious pavements typologies) is evaluated according to a series of criteria (the required features for these systems), a 
multi-criteria methodology is proposed both to automate and make the selection procedure more reliable. As pointed out by (Martin et al., 2007), the fundamental decision criteria that affect runoff management can be divided into technical, hydraulic, environmental, sociological, planning and economic aspects. Nonetheless, hydrology does not introduce significant differences in the decision-making process when the set of alternatives is limited to pervious pavements, due to their main typologies present a similarly adequate behaviour in this sense (CTC \& Associates LLC \& WisDOT Research \& Library Unit, 2012; US Environmental Protection Agency (Greening EPA), 2012). On the other hand, this paper proposes an inclusion of both technical and planning factors within the economic requirement, since this aspect comprises such implications too. In this respect, the fact that these systems are located within urban spaces also deserves to be highlighted, because this situation makes them especially sensitive to social and environmental factors.

Many different multi-criteria approaches have been developed throughout the years with the intention to deal with decision-making problems belonging to the construction field (Hokkanen \& Salminen, 1997; Al-Harbi, 2001; Wang \& Elhag, 2006; Zavadskas et al., 2014). Among them, the Integrated Value Model for Sustainable Assessments (MIVES) has demonstrated its worth when managing sustainable problems in complex scenarios (San-José Lombera \& Garrucho Aprea, 2010; Aguado et al., 2012; del Caño et al., 2012; Pons \& Aguado, 2012; Pons \& de la Fuente, 2013). Nevertheless, modelling the decision-making environment of urban pervious pavements involves several aspects, mainly related to the uncertainty and imprecision in data, which are unapproachable by a discrete methodology as MIVES. A support complement as Monte Carlo methods emerges to treat those variables that lack reliable sources of information, in order to assess the risk present when measuring them. Meanwhile, the set of criteria composing the decision-making problem are weighted by aggregating the opinions of a panel of experts in the field of study, according to the hierarchical levels of the Analytic Hierarchy Process (AHP). Since these comparisons are expressed in linguistic terms, the inclusion of Fuzzy sets is proposed to capture the ambiguity entailed by a human judgment. Considering all these elements, the resulting approach evolves to an integrated fuzzy stochastic MIVES method. 


\section{Methodology}

\subsection{Integrated Value Model for Sustainable Assessments (MIVES)}

The MIVES method, jointly developed by the Polytechnic University of Catalonia (UPC), Labein-Tecnalia and the University of the Basque Country (UPV/EHU), highlights for combining two powerful analytical concepts such as Multi-Criteria Decision Making Theory and Value Engineering (Miles, 1961; San-José Lombera \& Garrucho Aprea, 2010). This feature enables the conversion of any kind of measurement unit, either quantitative or qualitative, into a standardized value index, which postulates MIVES as an especially suitable tool for a balanced analysis as a sustainable assessment. Indeed, its successful utilization throughout the years has motivated its inclusion within the Spanish Structural Concrete Instruction (EHE-08) with sustainable purposes (Ministerio de la Presidencia, 2008).

The application process of this system to a generic problem comprises the design of a series of steps, which can be summarized in:

(1) Define the decision-making problem, according to the boundaries, context and organizational structure in which it is framed;

(2) Graphically depict the set of components and factors influencing the decisionmaking procedure, usually shaped in a three-level hierarchical tree composed of requirements, criteria and indicators;

(3) Determine the relative importance among the constituting elements at each level of the decision-making tree, by means of a weights assignment conducted either through the AHP method or by direct allocation;

(4) Establish a set of alternatives able to provide a feasible solution to the problem;

(5) Create the corresponding value function for each indicator by selecting the shape and parameters which suit best its nature, with the goal of transforming any likely value into a normalized index between 0 and 1; and 
(6) Assess the alternatives by aggregating the results calculated for the indicators until reaching the requirements level, thus obtaining an overall measurement of each alternative in sustainable terms.

Delving into the decision-making tree structure, the requirements can be defined as the set of general aspects which delimit and characterize the problem at a primary level. Each of these, in turn, is governed by a series of more specific criteria, whose fulfilment guarantees the satisfaction of the requirements. Both first levels are not submitted to direct evaluation, but they drag the results obtained in the third level of the tree, formed by the elements known as indicators, in where really resides the essence of the MIVES methodology.

The latter are evaluated using a mathematical formulation based on the concept of value function, which allows the conversion of any type of variable, regardless of their original nature, into a dimensionless value ranging from 0 to 1 . Such scale indicates the degree in which a certain alternative satisfies the fulfilment of an indicator. Value functions can adopt either increasing or decreasing shapes, so that the upper and lower limits may indicate minimum or maximum satisfaction degrees, depending on the indicator.

The analytical expression of these functions relies on five parameters, which define both their shape and type. Thus, the value of an indicator whose function evolves increasingly can be expressed as follows:

$$
V_{\text {ind }}=B \cdot\left[1-e^{-K_{i} \cdot\left(\frac{\left|x-x_{\text {min }}\right|}{C_{i}}\right)^{P_{i}}}\right]
$$

In Eq. (1): Xmin define the minimum value adoptable by the indicator; $x$ is the response of the alternative to this indicator; $\mathrm{P}_{i}$ is a factor which determines the shape of the function; $C_{i}$ and $K_{i}$ represent the values of the abscissa and the ordinate in the inflection point of the function, respectively; and B (Eq. (2)) is an adjusting component aimed to prevent any input from exceeding the scale limits. 


$$
\mathrm{B}=\left[1-\mathrm{e}^{-\mathrm{K}_{\mathrm{i}} \cdot\left(\frac{\left|\mathrm{x}_{\max }-\mathrm{x}_{\min }\right|}{\mathrm{C}_{\mathrm{i}}}\right)^{\mathrm{P}_{\mathrm{i}}}}\right]^{-1}
$$

Where $x_{\max }$ is the maximum achievable value by the alternative for the indicator at issue. In the case of a decreasing function, the only variations to the procedure described above consist of swapping the values of $X_{\min }$ and $X_{\max }$.

Figure 1 represents the importance of being accurate when selecting the shape parameters of each indicator, since this decision determines how the satisfaction level varies according to the zone to which the input value belongs. Thereby, an indicator which behaves linearly presents a range of inputs directly proportional to their value index. By contrast, the non-linear behaviours show some areas in where the satisfaction degree varies considerably: the initial and final stretch in the case of concave and convex shapes, and the middle zone in S-shaped functions (Pons \& Aguado, 2012).

Figure 1. Different shapes and parameters of the MIVES method

The overall sustainability index of an alternative is determined by the step-wise integration of the results obtained at the previous levels. Hence, the value index of an element in a certain level is calculated by aggregating the value indexes of its components at the previous level multiplied by their relative weight. The operation is implemented from the lower decision level, formed by the indicators, to the upper one, constituted by the set of alternatives (see Figure 2).

Figure 2. Aggregation procedure of value indexes

\subsection{Stochastic simulations}

It is common that some of the variables defining a decision-making problem are hardly characterizable discreetly, normally due to the lack of accurate information required to deterministically express the behaviour of an alternative regarding a certain criterion. 
In fact, what usually happens in reality is that the variables are definable by a range of expected behaviours according to the likelihood of achieving them, which necessitates the use of mechanisms able to process information stochastically. These simulations are implemented within the MIVES framework to reflect the non-deterministic character which may govern the value functions of some indicators.

\subsubsection{Monte Carlo methods}

The Monte Carlo methods are non-deterministic techniques usually employed to find approximate solutions to complex problems which are beyond the resources of theoretical mathematics by experimenting with random numbers. They have been used in many different disciplines throughout the last decades, among which operational research highlights for being one of the fields in which these methods are more widely applied (Hammersley \& Handscomb, 1964; McLeish, 2005). As a result of their versatility, several different derivations of the original concept have been developed according to the boundary conditions of each application branch, but, in any case, they all are characterized by the handling and interpretation of random numbers to solve a given problem.

Its implementation within the MIVES architecture is proposed for examining the effect that the uncertainty of some variables produces in achieving sustainable goals. In other words, the Monte Carlo method operates in this paper as a risk management tool aimed to show how likely is the consecution of a series of different sustainable performance degrees for a certain alternative. Such analysis could also be tackled by applying fuzzy techniques, but given the nature of the data, the authors considered stochastic simulations as the most effective approach (del Caño et al., 2012).

The set of indicators requiring an uncertainty analysis are easy to define by their most likely value, obtained from expertise and knowledge acquired from bibliography, and a lower and upper limit corresponding to the minimum and maximum values they might adopt. To develop the Monte Carlo method, a distribution function to model such data has to be chosen. The usefulness of the simulations is limited by the accuracy in which 
the selected distribution function fits the data defining the model, as well as by the quality of the estimates that have led to obtain the inputs.

From a range of estimates as the above explained, the generation of random numbers can be modelled by means of several different distribution functions. Thus, the triangular appears as the simplest option to design a probability distribution tending to favour the most likely value, by associating each of its vertices with the minimum, mode and maximum values (Vose, 1996). However, the presence of such vertices involves harsh inflections and, therefore, a lack of adjustment to the real distribution in these areas. In order to smooth them, the use of the Beta distribution based on the PERT (Program Evaluation Research Task) technique, also known as Beta-PERT distribution is proposed here. Since introduced by Malcolm et al. (Malcolm et al., 1959), many authors have dealt with the derivation of the Beta parameters $(\alpha, \beta)$ when developing a PERT simulation (Clark, 1962).

Let $x_{\min }, x_{\operatorname{m} . l}$ and $x_{\max }$ be the three values defining a certain variable; the mean $(\mu)$ and variance $\left(\sigma^{2}\right)$ for a Beta distribution can be respectively expressed as follows:

$$
\begin{aligned}
& \mu=x_{\min }-\left(x_{\max }-x_{\min }\right) \cdot\left(\frac{\alpha}{\alpha+\beta}\right) \\
& \sigma^{2}=\frac{\alpha \cdot \beta \cdot\left(x_{\max }-x_{\min }\right)^{2}}{(\alpha+\beta)^{2} \cdot(\alpha+\beta+1)}
\end{aligned}
$$

On the other hand, the PERT mathematical model calculates them as:

$$
\begin{aligned}
& \mu=\frac{x_{\min }+\lambda \cdot x_{\text {m.l. }}+x_{\text {max }}}{\lambda+2} \\
& \sigma^{2}=\frac{x_{\max }-x_{\text {min }}}{(\lambda+2)^{2}}
\end{aligned}
$$


where the default value for $\lambda$ is usually equal to 4 (Castro Fresno \& Aja Setién, 2005). Thus, taking $\lambda=4$, both pairs of expressions can be combined to obtain the Beta parameters $\alpha$ and $\beta$ for a PERT model:

$$
\begin{aligned}
& \alpha=\frac{2 \cdot\left(x_{\max }+4 \cdot x_{\operatorname{m.l}}-5 \cdot x_{\min }\right)}{3 \cdot\left(x_{\max }-x_{\min }\right)} \cdot\left[1+4 \cdot \frac{\left(x_{\mathrm{m} .1}-x_{\min }\right) \cdot\left(x_{\max }-x_{\mathrm{m} .1 .}\right)}{\left(x_{\max }-x_{\min }\right)^{2}}\right] \\
& \beta=\frac{2 \cdot\left(5 \cdot x_{\max }-4 \cdot x_{\mathrm{m} . l}-x_{\min }\right)}{3 \cdot\left(x_{\max }-x_{\min }\right)} \cdot\left[1+4 \cdot \frac{\left(x_{\mathrm{m} . l}-x_{\min }\right) \cdot\left(x_{\max }-x_{\mathrm{m} . \mathrm{l}}\right)}{\left(x_{\max }-x_{\min }\right)^{2}}\right]
\end{aligned}
$$

As pointed out by (Davis, 2008), from Eqs. (7) and (8), one infers that $4 \leq \alpha+\beta \leq 8$ in any case. Moreover, the maximum value (i.e. $\alpha+\beta=8$ ) is only reached when the mode coincides with the mean. Figure 3 illustrates the effect of varying the parameters $(\alpha, \beta)$ on the tendency of a Probability Density Function (P.D.F.) defined on an interval [0, 1], with $\mathrm{Xm}_{\mathrm{m} . \mathrm{l}}=\{0.1,0.2, \ldots, 0.9\}$.

Figure 3. Beta-PERT PDFs for the 3-tuple $\left[x_{\min }, x_{m . l}, x_{\max }\right]$ on the interval $[0,1]$

Hence, given a non-deterministic variable defined by the 3-tuple $\left[x_{\min }, x_{\operatorname{m.l}}, x_{\max }\right]$, the proposed Monte Carlo model consists of the generation of random numbers according to the Beta-PERT distribution above described, in order to obtain a range of occurrence probabilities of achieving different sustainable performances. Simply stated, once the simulation has finished, a set of possible $\mathrm{N}$ sustainability indexes is returned, being $\mathrm{N}$ the number of iterations compiled (del Caño et al., 2012). Tests show that from values of $\mathrm{N}$ close to 1000 results begin to converge with low computational cost (less than two seconds). Such results can be statistically used to plot both frequency histograms and cumulative probability curves, from which the decision-maker must ponder over the duality of risk and determine the most convenient course of action.

\subsection{Fuzzy weights assignment}

The aim at this stage is to establish the priorities among the elements governing the MIVES structure. This process can be carried out by various different methods, being 
the selected for this paper the Analytic Hierarchy Process (AHP). However, since this technique is not capable of capturing the vagueness present in a subjective comparison, its utilization is combined with Fuzzy Sets to deal with such ambiguity. Nevertheless, even taking into account aspects as uncertainty and imprecision, the quality of a judgment is still directly proportional to the knowledge of the person issuing it. For this reason, leaving the execution of this process to one single person is not recommendable, being more expedient to gather the views of a group of people with expertise in the evaluated subject, whose assessments can be integrated by using the said fuzzy AHP method, in order to reach a commitment result which really reflects the interrelationships among the components of the decision-making problem.

\subsubsection{Analytic Hierarchy Process (AHP)}

The Analytic Hierarchy Process, created by Saaty (Saaty, 1980), has been widely utilized within the construction sector (Ei-Mikawi \& Mosallam, 1996; Kalamaras et al., 2000; Lin et al., 2008; Zavadskas et al., 2011), often as a system for weighting the relative importance among the set of criteria that compose a decision-making problem (Saaty, 1990). Generally, the structure of these problems comprises a series of stepped levels, so that several pairwise comparisons are established to obtain the inner hierarchy among its constituting elements, depending on their contribution degree to the higher level to which they are linked. To quantify this, (Saaty, 1980) proposed a comparison scale whose values are shown in Table 1.

Table 1. Saaty's comparison scale

If element $\mathrm{i}$ has one certain value with respect to another element $\mathrm{j}$, then $\mathrm{j}$ has the reciprocal value when compared with i. To state it in a different manner, by applying Saaty's scale, a nxn reciprocal comparison matrix [A] can be obtained, whose elements verify the expression $a_{i j}{ }^{*} a_{j i}=1$. Thus, the top right triangle of the matrix is formed by a series of elements which are the reciprocals of the ones belonging to the bottom left triangle (Skibniewski \& Chao, 1992). The consistency of the comparisons made is measured through the calculation of the maximum eigenvalue of the matrix 
$\left(\lambda_{\max }\right)$, whose corresponding eigenvector determines the relative priorities among the analyzed criteria.

In this manner, the comparison matrix is totally consistent when $\lambda_{\max }$ is equal to $\mathrm{n}$, whilst the inconsistency increases as the eigenvalue grows. In order to appraise this aspect, (Saaty, 1980) developed the concept of consistency ratio (C.R.), which, in turn, consists of two more elements: consistency index (C.I.) and random consistency index (R.I.). The first one is expressed as follows:

$$
\text { C. I. }=\frac{\lambda_{\max }-\mathrm{n}}{\mathrm{n}-1}
$$

Meanwhile, the random consistency index is the measure of all the consistency indexes of a comparison matrix which has been randomly generated. Thereby, it only depends on the size of the matrix (n) and takes the following values according to it (see Table 2).

Table 2. Random Consistency Index

Finally, the consistency ratio is defined as the ratio between both of them. A matrix can be considered as consistent when the value of this ratio is less than 0.1 (see Eq. (10)). This limit indicates that the inconsistency must not exceed $10 \%$ of the average inconsistency of the whole set of comparison matrices:

C. R. $=\frac{\text { C.I. }}{\text { R.I. }}<0.1$

\subsubsection{Fuzzy sets}

Given its discrete nature, the traditional AHP approach above explained entails a series of weaknesses which have been thoroughly discussed under several different points of view. In other words, the capacity of the conventional AHP method to capture decision-makers real perceptions and opinions is limited. Inherent aspects of human judgments as vagueness and imprecision are difficult to be expressed by using the 
crisp scale shown in Table 1, which has motivated a development in fuzzy decisionmaking methods (Buckley, 1985; Cheng, 1999). From this point, several fuzzy AHP approaches have been carried out throughout the last years (Pan, 2008; Jaskowski et al., 2010; Fazel Zarandi et al., 2011).

Fuzzy logic was originally introduced by (Zadeh, 1965) to deal with the uncertainty and ambiguity that surround real world problems. One of the most significant and intuitive ways to handle fuzziness is the use of fuzzy numbers, whose definition includes the concept of membership degree. (Zadeh, 1965) proposed that the range of membership values of an element to a set may vary within the interval [0, 1], instead of having to be limited to one of the pair of values $\{0,1\}$. Thereby, given a fuzzy set $F$, a fuzzy number can be characterized by a membership function $\mu_{\mathrm{A}}(\mathrm{x})$ which represents the grade of membership of $x$ in $F$ (Lin, 2010). Thus, a triangular fuzzy number, which is the selected type to be used in this paper, is defined as $\tilde{a}_{i j}=\left(\alpha_{i j}, \beta_{i j}, \gamma_{i j}\right)$, being its membership function the following:

$$
\mu_{\mathrm{A}}(\mathrm{x} ; \alpha, \beta, \gamma)=\left\{\begin{array}{lc}
\frac{\mathrm{x}-\alpha}{\beta-\alpha}, & \alpha \leq x \leq \beta \\
\frac{\gamma-\mathrm{x}}{\gamma-\beta}, & \beta \leq x \leq \gamma \\
0, & \text { otherwise }
\end{array}\right.
$$

where $\alpha, \beta$ and $y$ are the lower, middle and upper values of the triangular fuzzy number ã. By applying these concepts, the original Saaty's pairwise scale is derived as shown in Table 3.

Table 3. Fuzzy comparison scale

The conversion from crisp to fuzzy is not a rigid procedure, which means that the decision-maker is able to choose both the limits and the value of $\delta$ which best fit their specific problem. In this paper, a value of $\delta=2$ has been adopted as a wide enough margin to represent fuzziness consistently. Besides, unlike some authors who only used odd fuzzy numbers (Cheng, 1997; Deng, 1999), the proposed model also 
includes their intermediate values (denoted by adding + or - to the adjacent linguistic term, as appropriate), in order to provide a continuous range of comparison degrees (Srdjevic \& Medeiros, 2008).

Thus, given the crisp judgments provided by a group of experts according to Saaty's scale (see Table 1), a set of comparison matrices formed by triangular fuzzy numbers can be generated by applying the conversion rules described in Table 3 . Their level of consistency must be ascertained by checking Eq. (9). As pointed out by (Csutora \& Buckley, 2001), if the crisp comparison matrix is consistent, then the fuzzy matrix is consistent.

Analytically, let $\tilde{A}_{\mathrm{i}, \mathrm{k}}=\left[\left(\alpha_{\mathrm{ij}}, \beta_{\mathrm{ij}}, \gamma_{\mathrm{ij}}\right)\right]$ be the fuzzy comparison matrix between two criteria $i$ and $j$ obtained from the original crisp matrix $A_{i j, k}=\left[\beta_{i j}\right]$ provided by an expert $k(k=1$, $2,3, \ldots n$ ). By applying Eqs. (9) and (10), it is checked if the calculated C.R. for $A_{i j, k}$ is less than 0.1 , in which case the fuzzy matrix $\tilde{A}_{i, k}$ can be considered as consistent. Otherwise, the expert must review his original assessments until they show a sufficiently high consistency level.

\subsubsection{Defuzzification}

After checking the consistency of the fuzzy matrices, their resulting components must be defuzzified to finally obtain a set of discrete values. This process can be developed in several different ways, being the selected one for this paper the proposed by (Opricovic \& Tzeng, 2003), known as the Converting Fuzzy data into Crisp Scores method (CFCS). The reasons why this method has been chosen are based on its intuitive character and ease of application.

The principles of this methodology can be synthetized algorithmically, which results in the following sequence of steps:

1. Normalize the fuzzy matrices: 


$$
\begin{aligned}
& x \alpha_{i j, k}=\frac{\alpha_{i j, k}-\min \alpha_{i j, k}}{\Delta_{\min }^{\max }} \\
& x \beta_{i j, k}=\frac{\beta_{i j, k}-\min \alpha_{i j, k}}{\Delta_{\min }^{\max }} \\
& x \gamma_{i j, k}=\frac{\gamma_{i j, k}-\min \alpha_{i j, k}}{\Delta_{\min }^{\max }}
\end{aligned}
$$

where $\quad \Delta_{\min }^{\max }=\max \gamma_{\mathrm{ij}, \mathrm{k}}-\min \alpha_{\mathrm{ij}, \mathrm{k}}$

2. Calculate the lower and upper normalized values:

$$
\begin{aligned}
& x \alpha s_{i j, k}=\frac{x \beta_{i j, k}}{1+x \beta_{i j, k}-x \alpha_{i j, k}} \\
& x \gamma s_{i j, k}=\frac{x \gamma_{i j, k}}{1+x \gamma_{i j, k}-x \beta_{i j, k}}
\end{aligned}
$$

3. Obtain the total normalized crisp values:

$$
x_{i j, k}=\frac{x \alpha s_{i j, k} \cdot\left(1-x \alpha s_{i j, k}\right)+x \gamma s_{i j, k}}{1-x \alpha s_{i j, k}+x \gamma s_{i j, k}}
$$

4. Compute the crisp values:

$$
\mathrm{a}_{\mathrm{ij}, \mathrm{k}}^{*}=\min \alpha_{\mathrm{ij}, \mathrm{k}}+\mathrm{x}_{\mathrm{ij}, \mathrm{k}} \cdot \Delta_{\min }^{\max }
$$

5. Integrate the crisp values:

$$
a_{i j}^{*}=\left(\prod_{k=1}^{m} a_{i j, k}^{*}\right)^{1 / m}
$$


From this point, an overall pairwise comparison matrix containing the set of crisp values obtained from the synthesis of the individual assessments provided by each expert can be established:

$$
\mathrm{A}_{\mathrm{ij}}^{*}=\left[\mathrm{a}_{\mathrm{ij}}^{*}\right]
$$

The final weights which will be used to perform the analysis are obtained by applying Eq. (22):

$$
w_{i}=\frac{\left(\prod_{j=1}^{n} a_{i j}^{*}\right)^{1 / n}}{\sum_{i=1}^{n}\left(\prod_{j=1}^{n} a_{i j}^{*}\right)^{1 / n}}
$$

\section{Application to pervious pavements}

In order to address a general situation, the proposed MIVES methodology was applied to select the most suitable pervious pavement type for the rehabilitation of a light traffic urban road placed in the north of Spain and not surrounded by special conditions in both architectural and environmental terms; i.e. a case in which the conditions are similar for any alternative, with the aim of establishing an unbiased and equable comparison. Moreover, although transport distances do not introduce significant deviations either, they have been also included in the analysis.

The following subsections are structured to apply the steps of MIVES listed in Section 2.1 to the selection procedure of urban pervious pavements:

\subsection{Design of the decision-making tree}

Designing the requirements tree is a crucial aspect within the MIVES procedure. A poor selection at this stage would surely lead to a bad reflection of the decision-maker's original prospects. To avoid such circumstance, a vast array of bibliography was 
consulted (ACl Committee 522, 2008; National Asphalt Pavement Association (NAPA), 2008; US Environmental Protection Agency (Greening EPA), 2012; Interlocking Concrete Pavement Institute (ICPI), 2014). As a result, the decision-making tree represented in Table 4 emerged.

Table 4. Proposed decision-making tree

A good indicator must be both representative and discriminant; i.e. regardless how enlightening a certain variable may be, it will not provide any additional information if each of the different alternatives presents a similar performance in this respect. Under this premise, the decision-making tree depicted in Table 4 is composed of a total of nineteen indicators, each of which is considered descriptive and exclusionary enough.

The economic requirement includes nine indicators, from which those related to cost and efficiency issues have been elaborated from the data contained in several Spanish Construction Budgetary Bases (Consejería de Fomento, Vivienda, Ordenación del Territorio y Turismo del Gobierno de Extremadura, 2012; Atayo, 2013; Consejería de Fomento y Vivienda de Andalucía, 2013). Considering the uncertainty that a set of fixed values as these involves, they have been slightly altered according to market tendencies in order to obtain a separate 3-tuple as minimum, most likely and maximum values, thus forming stochastic variables $\left[x_{\min }, x_{m . l .}, x_{\max }\right]$. Same situation occurs with I 1.3.1, whose inputs oscillate between a lower and upper limit obtained from material properties and experience. The remaining indicator of time, I 1.3.4, adopts a discrete value based on the curing age of the surface materials in each case. Finally, I 1.2.1 and 1.2.2 describe the flexibility degree of the alternative in terms of economy. The first, which also has a deterministic quantitative nature, refers to the minimum needs of material supply for each alternative, whilst I 1.2 .2 varies in accordance with a punctuation scale which reflects the sensitivity of the alternative against climate conditions at the construction stage.

Due to the development of a complete Life Cycle Assessment (LCA) would exceed the proportions of this paper, the environmental requirement comprises a simplified view of three of LCA's fundamental aspects, which are Consumptions, Emissions and 
Recyclability. Thus, the Pavement Life-cycle Assessment Tool for Environmental and Economic Effects (PaLATE), created at the University of California (Berkeley) (Horvath, 2004), was used to measure both the Energy consumption and the $\mathrm{CO}_{2}$ emissions corresponding to each of the pavement types under analysis for a same period of 30 years. Since this tool was developed in 2003, it was considered appropriate to adjust their reference values with those proposed in the Inventory of Carbon \& Energy database (ICE) (Hammond \& Jones, 2011). This lack of update is also the reason why other consumption and emission categories have not been included, such as water consumptions or $\mathrm{NO}_{x}, \mathrm{PM}_{10}$ and $\mathrm{SO}_{2}$ emissions. Meanwhile, the criterion defined as Recyclability focuses on the duality between raw and recyclable materials, pointing to the required mass for the first ones and the admission degree of the latter, respectively.

The social requirement is a synergy among the three following criteria: Aesthetics, Comfort and Safety. Regarding the first, I 3.1.1 refers to the range of shapes, colours and textures in which the paving can be fabricated, whereas I 3.1.2 indicates the degree in which the solution is adapted to the urban environment. Meanwhile, I 3.2.1 shows the impact of roughness in citizens' comfort, either by the noise or the discommodity in transit that a rugged paving implies. The next indicator is the only within the social requirement which is measured quantitatively, specifically through the Albedo coefficient (Heat Island Group, 2014). Thus, the Urban Heat Island effect is estimated by means of the reflecting power of each surface of the incident radiation upon it. As far as the last criterion is concerned, I 3.3.1 shows how susceptible the different pavements are to be affected by vandalism (e.g. their ease of disassembly or the sensitivity to be ruined during their curing phase). Lastly, possible damages to labour and users, whether physical or atmospheric, are contained in the indicator I 3.3.2.

\subsection{Weighting of the decision-making tree}

Once the hierarchical structure of the tree was defined, a group of ten experts was requested to give their assessments regarding the relative importance among their 
components. Moreover, such panel of experts was composed by representatives from all sectors, from private companies to public administration to research groups, in order to obtain a balanced view of the problem. Thereby, a series of questionnaires was elaborated based on the decision-making tree (see Table 4), so that the experts who agreed to participate sent back their pairwise comparisons relating to each of the three decision levels. Starting from the linguistic terms of the crisp scale originally proposed by (Saaty, 1980), questions such as "How important is element i compared to element j?" were the base of these inquiries. The results thus obtained are shown in Table 5.

Table 5. Experts' judgments regarding each of the three decision-level

\subsection{Description of alternatives}

Experience and bibliography show that three major pavement typologies are the most commonly selected alternatives to perform as stormwater management systems: porous asphalt, porous concrete and interlocking concrete pavers. According to the specifications contained in specialized literature (ACI Committee 522, 2008; Minnesota Stormwater Steering Committee, 2008, National Asphalt Pavement Association (NAPA), 2008; US Environmental Protection Agency (Greening EPA), 2012; Interlocking Concrete Pavement Institute (ICPI), 2014), the cross sections illustrated in Figure 4 are selected to develop the model.

Figure 4. Proposed cross-sections of the three major pavement types

\subsection{Definition of the value functions}

Some of the indicators defined in Table 4 are difficult to value deterministically, because they measure properties on which there is no certain knowledge, but rather an expected response. As pointed out in Section 3.1, these indicators are those dependent on both economic and materials-related factors. In this context, expressing them by discrete values is far from being an accurate and methodologically adequate approach. Instead, their variable nature can be properly model through a distribution function tending to favour their most-likely values as Beta-PERT. 
A summary of the characteristics of each indicator is represented in Table 6, where "Type" indicates how their level of satisfaction evolves (D = Decreasing / I = Increasing) and "Nature" the type of variable they are in statistical terms ( $D=$ Deterministic / S = Stochastic). Most likely values for stochastic indicators are provided for each alternative $(\mathrm{PA}=$ Porous Asphalt; $\mathrm{PC}=$ Porous Concrete; $\mathrm{ICP}=$ Interlocking Concrete Pavers).

Table 6. Descriptive characteristics of the set of indicators

\subsection{Assessment of alternatives and discussion}

The data contained in Table 5 was processed by the fuzzy AHP methodology previously described to obtain the set of relative weights of each of the components of the decision-making tree represented in Table 4. Then, the MIVES procedure was introduced to calculate the value indexes of each indicator by applying Eqs. (1) and (2), according to the parameters depicted in Table 6. Both sets of results were finally integrated to determine the overall value index for each of the alternatives, as shown in Figure 5. Since partial results are also a valuable source of information, the performances of the three pavement types regarding the three requirements are also displayed in such illustration.

Figure 5. Overall and partial value indexes of each alternative

The results support the competition between these three types of pavement because, as it can be observed, their differences in overall terms are small. Furthermore, while interlocking concrete pavers' alternative falls slightly behind the rest, porous asphalt and porous concrete stay closer, to the point of sharing a common area of sustainable performance. To reinforce the final decision-making, it is advisable to also address the performance of each alternative with respect to the requirements. In this regard, each of the alternatives highlights over the rest in one of the three main aspects. Thus, porous asphalt appears as the most economical solution, mainly due to its low construction cost in comparison with the other alternatives. Also in this sense, despite of its excellent ratings in several economic indicators (e.g. "Minimum batch size", "Sensitivity to climate conditions" or "Longevity"), the interlocking concrete pavers' 
alternative is strongly penalized by its commonly large installation costs. On the other hand, this solution reaches the highest value in the second requirement thanks to its balanced behaviour in each of the three environmental criteria, although experience with porous asphalt in terms of recyclability puts it very close to that. Finally, porous concrete clearly outperforms the other alternatives in regard to the last requirement, because of its extremely regular response to the whole set of social indicators. In contrast, both Porous Asphalt and Interlocking Concrete Pavers exhibit poor performances in relation indicators such as "Appearance" or "Urban heat island" and "Roughness" or "Susceptibility to vandalism", respectively.

\section{Conclusions}

This paper proposes and validates a new multi-criteria model based on the combination of several existing decision making tools. The core of this model resides in the MIVES methodology, whose step-wise architecture is improved here by including some auxiliary complements such as Monte Carlo Simulations, Fuzzy Sets and the AHP method. Thereby, the variability of indicators values can be stochastically modelled through Beta-PERT distribution functions when needed, whilst the weights assignment stage is carried out by synthetizing the opinions of a group of experts by integrating a Fuzzy AHP approach with the CFCS method. The synergic performance of these elements is aimed to provide an added quality when facing decision making problems involving conflicting criteria under uncertain environments, especially when the assessment is performed in sustainable terms.

The inputs used for the application of this methodology to the selection of pervious pavements are (1) a specific decision-making hierarchy tree, (2) the value functions defining the features of the pavements and (3) the pairwise comparison judgments provided by a group of ten experts. The output is a probability density function of the likely overall value indexes for each of the three studied alternatives. The results show the usefulness of the model and the clairvoyance that provides decision-makers to select the most suitable pavement type. Furthermore, although properly choosing the most adequate pervious pavement can make a difference in the standard of living of 
an urban space, there is no similar application destined to the selection of these structures, which further increases the importance of the proposed approach. Undoubtedly, this methodology can be also implemented in any other decision-making activity involving uncertainty and expert knowledge, regardless of the field to which it belongs. In addition, the conception stage presented in this paper is subject to discussion, both concerning the design of the hierarchical structure of the problem and the definition of the value functions and the weights comparison scale. Such aspects also depend on the specifics of each case of application.

Due to the success of this model, a research line is being developed to implement its underlying methodology in the pavement rehabilitation of entire cities. The aim is to improve the hydrologic efficiency of these urban areas by proposing the most suitable pervious pavement structure to be installed in each current section of road infrastructure susceptible of being rehabilitated.

\section{Acknowledgments}

This paper was possible thanks to the research project entitled "Hydrological Rehabilitation of Urban Road Infrastructures (RHIVU)" (Ref. BIA2012-32463) financed by the Ministry of Economy and Competitiveness with the PGE of the Spanish Government and FEDER funds. The authors also wish to express their appreciation to the expert panel that contributed to enrich the quality of this paper, whose members proceed from the following entities: GITECO (University of Cantabria), Tauw, University of the Sunshine Coast, Urgarbi, San Sebastián City Council, SUDS ARG (Coventry University), Barcelona City Council, PMEnginyeria and SUDS-ATLANTIS.

\section{References}

ACI Committee 522. (2008). Specification for pervious concrete pavement

Aguado, A., Caño, A., de, I. C., Gómez, D., \& Josa, A. (2012). Sustainability assessment of concrete structures within the spanish structural concrete code. 
Journal of Construction Engineering and Management, 138(2), 268-276. doi:10.1061/(ASCE)CO.1943-7862.0000419.

Al-Harbi, K. M. A. (2001). Application of the AHP in project management. International Journal of Project Management, 19(1), 19-27. doi:10.1016/S0263-7863(99)000381.

Atayo, S. A. (2013). Base de precios PREOC.

Buckley, J. J. (1985). Fuzzy hierarchical analysis. Fuzzy Sets and Systems, 17(3), 233247. doi:10.1016/0165-0114(85)90090-9.

Castro Fresno, D., \& Aja Setién, J. L. (2005). Organización y control de obras. Santander (Cantabria): Servicio de Publicaciones de la Universidad de Cantabria.

Castro-Fresno, D., Andrés-Valeri, V. C., Sañudo-Fontaneda, L. A., \& RodriguezHernandez, J. (2013). Sustainable drainage practices in spain, specially focused on pervious pavements. Water, 5(1), 67-93. doi:10.3390/w5010067.

Cheng, C. (1997). Evaluating naval tactical missile systems by fuzzy AHP based on the grade value of membership function. European Journal of Operational Research, 96(2), 343-350. doi:10.1016/S0377-2217(96)00026-4.

Clark, C. E. (1962). The PERT model for the distribution of an activity time. Operations Research, 10(3), 405-406.

Consejería de Fomento y Vivienda de Andalucía. (2013). Base de costes de la construcción de andalucía (BCCA) 2013.

Consejería de Fomento, Vivienda, Ordenación del Territorio y Turismo del Gobierno de Extremadura. (2012). Base de precios de la construcción 2012.

Csutora, R., \& Buckley, J. J. (2001). Fuzzy hierarchical analysis: The lambda-max method.

CTC \& Associates LLC, \& WisDOT Research \& Library Unit. (2012). Comparison of permeable pavement types: Hydrology, design, installation, maintenance and cost. Wisconsin: WisDOT Southeast Region. 
Davis, R. (2008). Teaching project simulation in excel using PERT-beta distributions. INFORMS Transactions on Educations, 8(3), 139-148.

del Caño, A., Gómez, D., \& de la Cruz, M. P. (2012). Uncertainty analysis in the sustainable design of concrete structures: A probabilistic method. Construction and Building Materials, 37(0), 865-873. doi:10.1016/j.conbuildmat.2012.04.020.

Ei-Mikawi, M., \& Mosallam, A. S. (1996). A methodology for evaluation of the use of advanced composites in structural civil engineering applications. Composites Part B: Engineering, 27(3-4), 203-215. doi:10.1016/1359-8368(95)00030-5.

Fresno, D. C., Bayón, J. R., Hernández, J. R., \& Muñoz, F. B. (2005). Sustainable urban drainage systems (SUDS). Interciencia, 30(5), 255-260-306-308.

Hammersley, J. M., \& Handscomb, D. C. (1964). Monte carlo methods. London: Methuen.

Hammond, G., \& Jones, C. (2011). Inventory of carbon \& energy (ICE) version 2.0. (). University of Bath, UK.

Heat Island Group. (2014). Cool science: Cool pavements. Retrieved from http://heatisland.Ibl.gov/coolscience/cool-science-cool-pavements

Hokkanen, J., \& Salminen, P. (1997). Choosing a solid waste management system using multicriteria decision analysis. European Journal of Operational Research, 98(1), 19-36. doi:10.1016/0377-2217(95)00325-8.

Horvath, A. (2004). Pavement life-cycle assessment tool for environmental and economic effects (PaLATE): User manual. University of California, Berkeley.

Lin, H. (2010). An application of fuzzy AHP for evaluating course website quality. Computers \& Education, 54(4), 877-888. doi:10.1016/j.compedu.2009.09.017.

Malcolm, D. G., J. H. Roseboom, J. H., Clark, C. E., \& Fazar, W. (1959). Application of a technique for research and development program evaluation. Operations Research, 7(5), 646-669.

Martin, C., Ruperd, Y., \& Legret, M. (2007). Urban stormwater drainage management: The development of a multicriteria decision aid approach for best management 
practices. European Journal of Operational Research, 181(1), 338-349. doi:10.1016/j.ejor.2006.06.019.

Miles, L. D. (1961). Techniques of value analysis and engineering. New York: McGrawHill.

Ministerio de la Presidencia (Ed.). (2008). Real decreto 1247/2008, de 18 de julio, por el que se aprueba la instrucción de hormigón estructural (EHE-2008).

Miri-Nargesi, S. S., Keramati, A., Ansarinejad, A., \& Nazari-Shirkouhi, S. (2011). A structured methodology for information systems outsourcing decisions using fuzzy MCDM. Proceedings of the 2011 International Conference on Industrial Engineering and Operations Management, 445-450.

Opricovic, S., \& Tzeng, G. -. (2003). Defuzzification within a multicriteria decision model. International Journal of Uncertainty, Fuzziness and Knowlege-Based Systems, 11(5), 635-652. doi:10.1142/S0218488503002387.

Pan, N. (2008). Fuzzy AHP approach for selecting the suitable bridge construction method. Automation in Construction, 17(8), 958-965. doi:10.1016/j.autcon.2008. 03.005 .

Pons, O., \& Aguado, A. (2012). Integrated value model for sustainable assessment applied to technologies used to build schools in Catalonia, Spain. Building and Environment, 53(0), 49-58, doi:10.1016/j.buildenv.2012.01.007.

Pons, O., \& de la Fuente, A. (2013). Integrated sustainability assessment method applied to structural concrete columns. Construction and Building Materials, 49(0), 882-893. doi:10.1016/j.conbuildmat.2013.09.009.

Pratt, C. Wilson, S., \& Cooper, P. (2002). Source control using constructed pervious surfaces. hydraulic, structural and water quality performance issues (CIRIA C582, RP637 ed.). London: CIRIA.

Saaty, T. L. (1980). The analytic hierarchy process: Planning, priority setting, resource allocation McGraw-Hill International Book Co.

Saaty, T. L. (1990). How to make a decision: The analytic hierarchy process. European Journal of Operational Research, 48(1), 9-26. 
San-José Lombera, J., \& Garrucho Aprea, I. (2010). A system approach to the environmental analysis of industrial buildings. Building and Environment, 45(3), 673-683. doi:10.1016/j.buildenv.2009.08.012.

Skibniewski, M., \& Chao, L. (1992). Evaluation of advanced construction technology with AHP method. Journal of Construction Engineering and Management, 118(3), 577-593. doi:10.1061/(ASCE)0733-9364(1992)118:3(577).

Srdjevic, B., \& Medeiros, Y. D. P. (2008). Fuzzy AHP assessment of water management plans. Water Resources Management, 22(7), 877-894. doi:10.1007/ s11269-007-9197-5.

US Environmental Protection Agency (Greening EPA). (2012). Stormwater management best practices. Retrieved from http://www.epa.gov/oaintrnt/ stormwater/best_practices.htm

Vose, D. (1996). Risk analysis: A quantitative guide. New York: John Wiley \& Sons.

Wang, Y., \& Elhag, T. M. S. (2006). Fuzzy TOPSIS method based on alpha level sets with an application to bridge risk assessment. Expert Systems with Applications, 31(2), 309-319. doi:10.1016/j.eswa.2005.09.040.

Zadeh, L. A. (1965). Fuzzy Sets, Information and Control, 338-353.

Zavadskas, E. K., Vilutienè, T., Turskis, Z., \& Šaparauskas, J. (2014). Multi-criteria analysis of projects' performance in construction. Archives of Civil and Mechanical Engineering, 14(1), 114-121. doi:10.1016/j.acme.2013.07.006. 
Figures
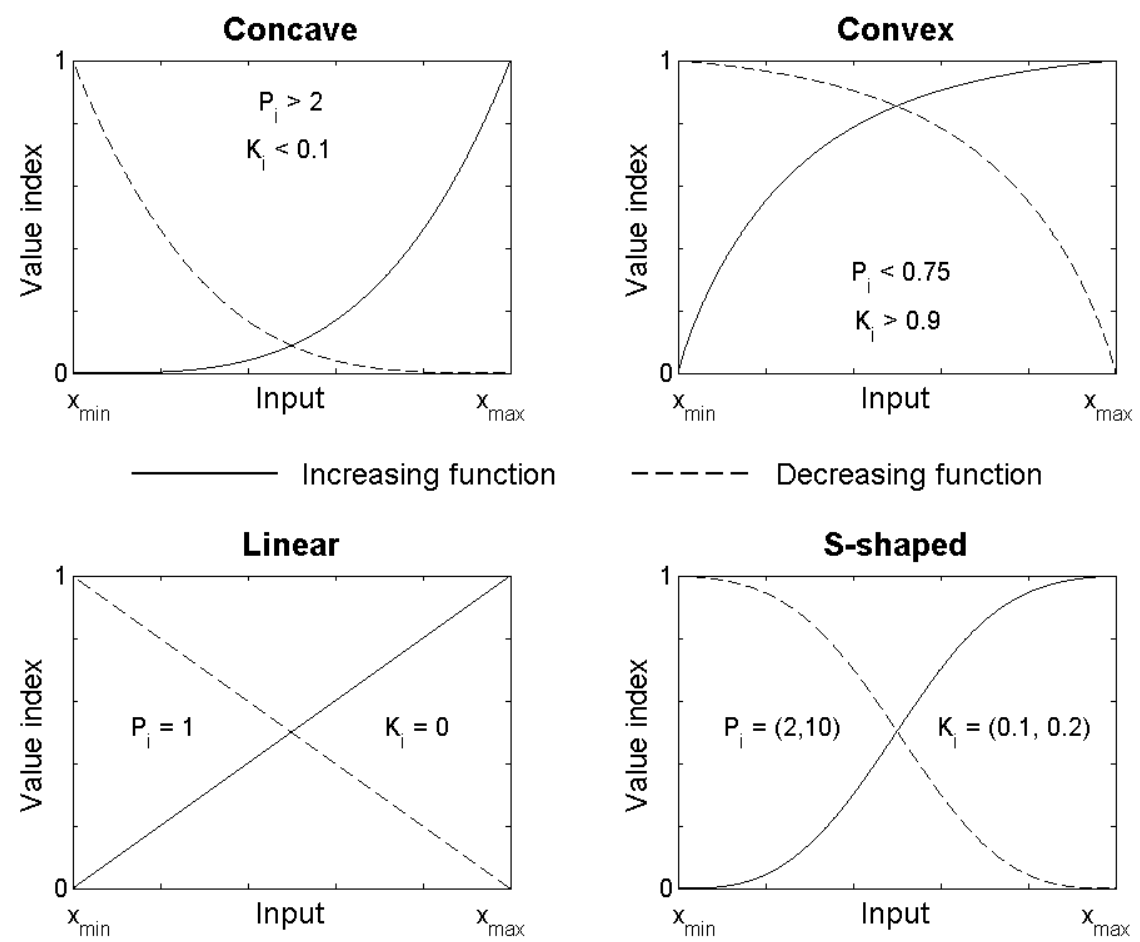

Figure 1. Different shapes and parameters of the MIVES method 


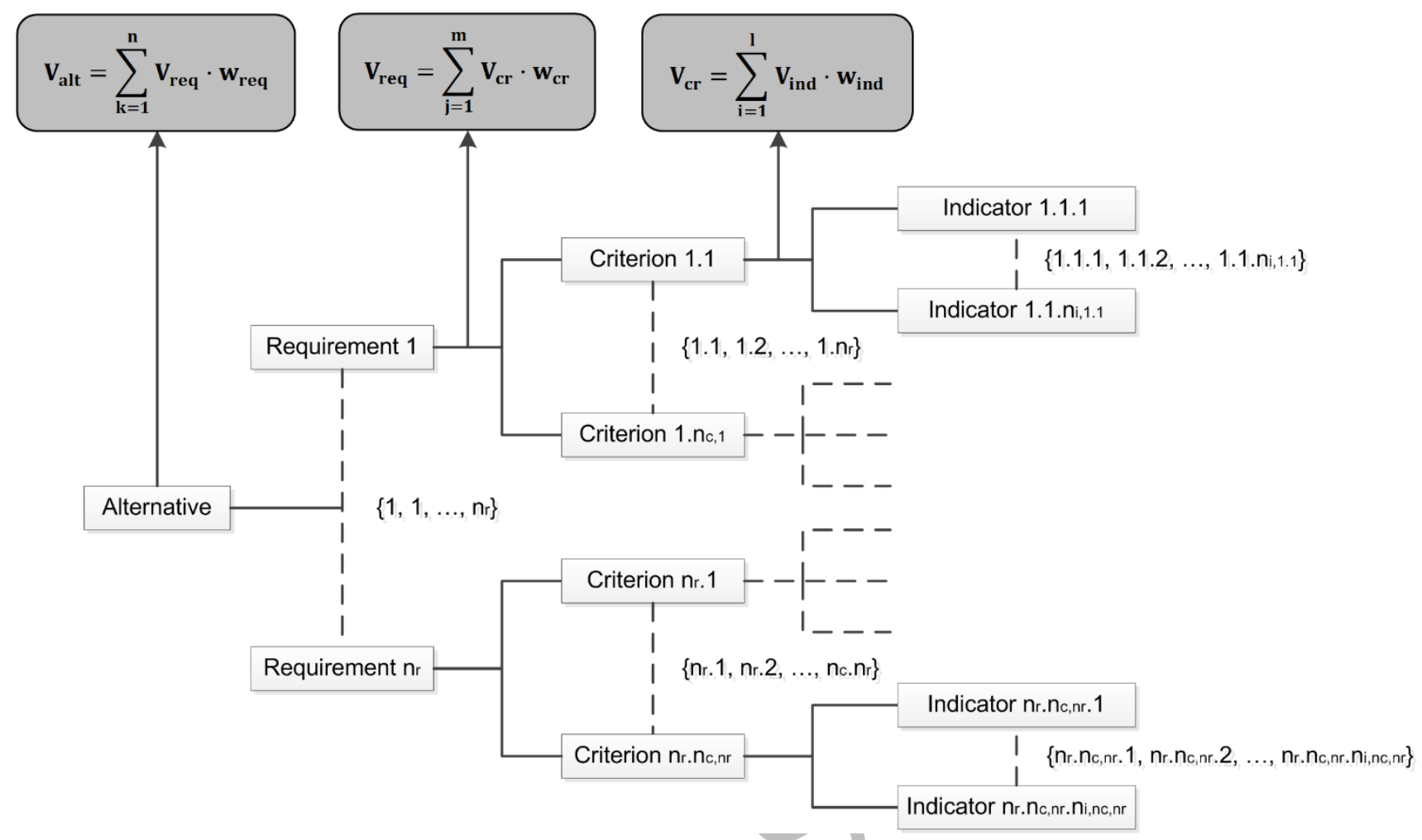

Figure 2. Aggregation procedure of value indexes 


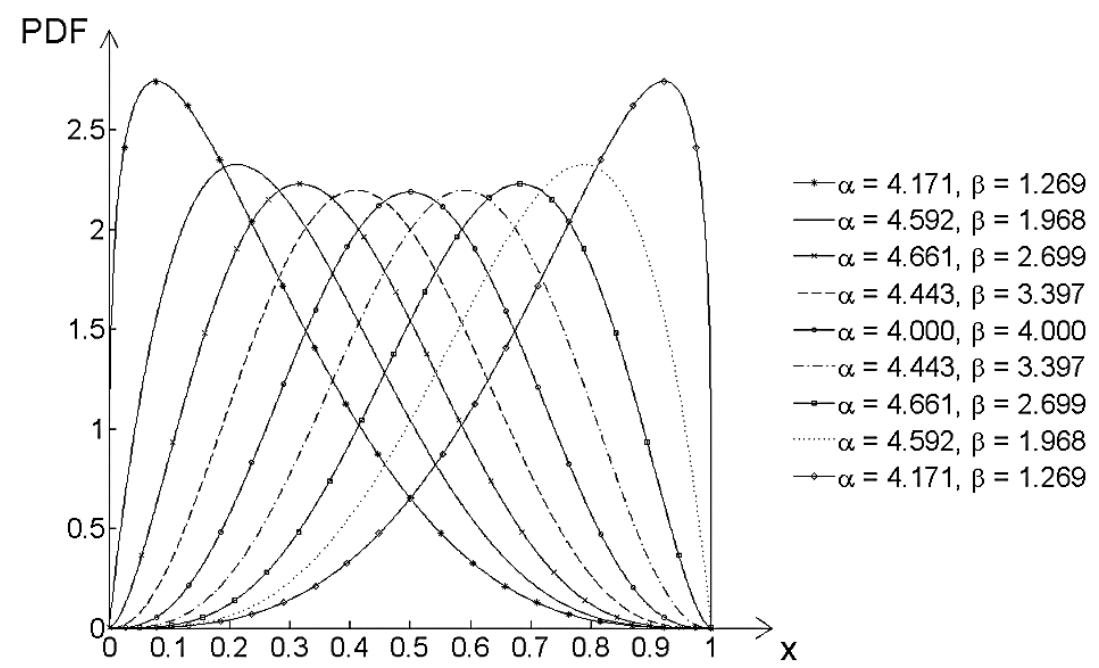

Figure 3. Beta-PERT PDFs for the 3-tuple $\left[x_{\min }, x_{m . l .}, x_{\max }\right]$ on the interval $[0,1]$ 

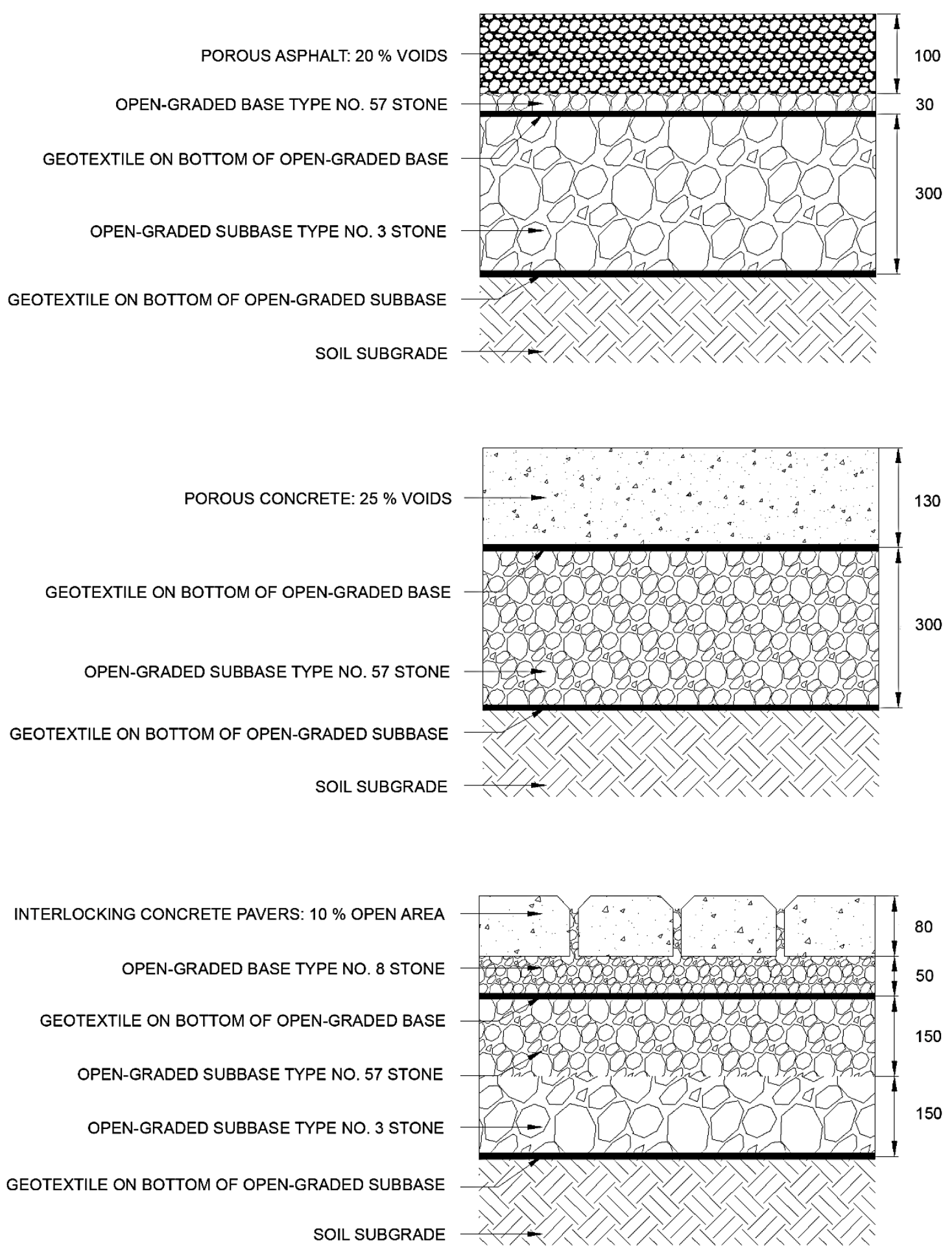

DIMENSIONS IN MM

Figure 4. Proposed cross-sections of the three major pavement types 

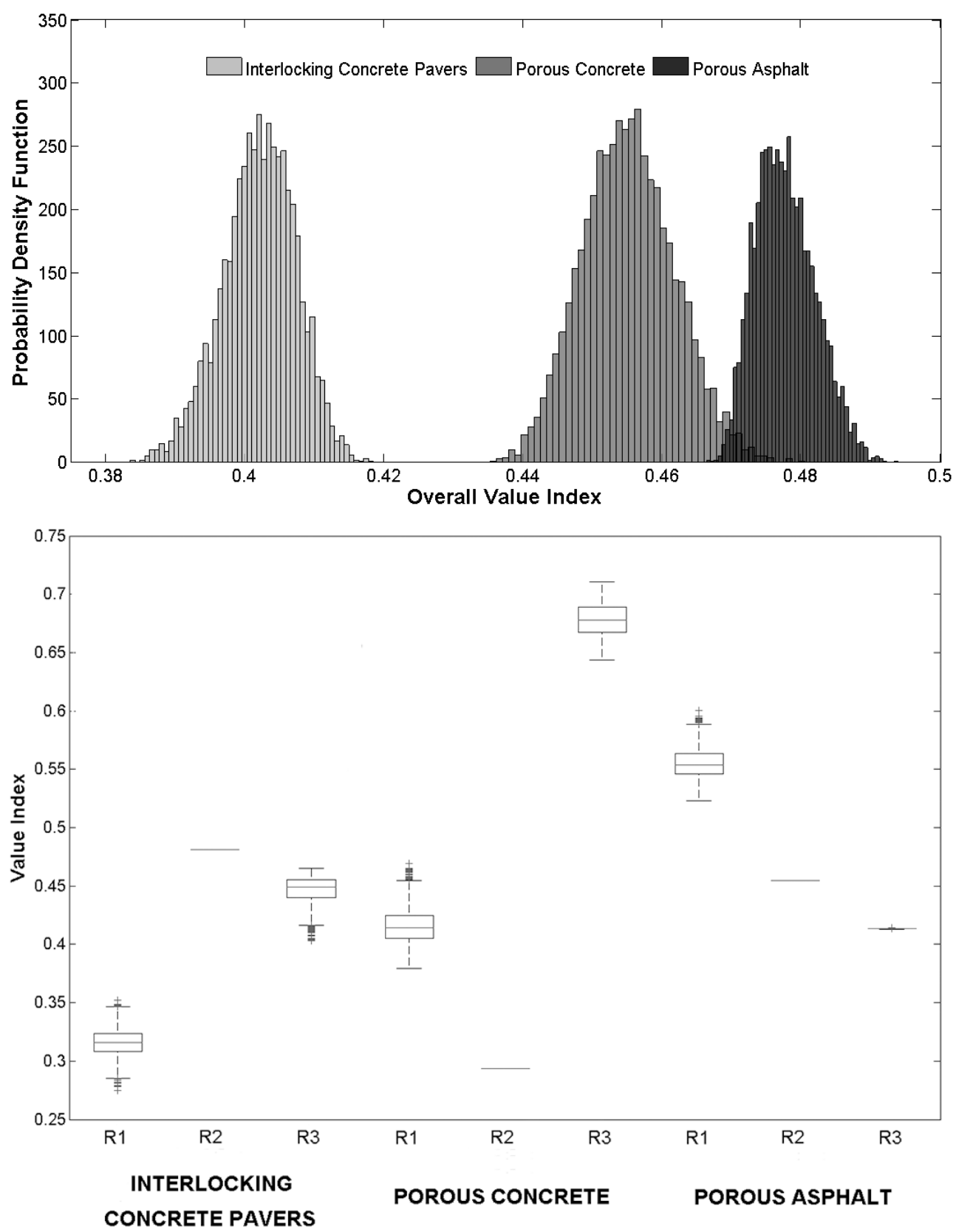

Figure 5. Overall and partial value indexes of each alternative 


\section{Tables}

Table 1. Saaty's comparison scale

\begin{tabular}{lc}
\hline Linguistic term & Numerical value \\
\hline Equally important & 1 \\
Slightly more important & 3 \\
More important & 5 \\
Much more important & 7 \\
Absolutely more important & 9 \\
Intermediate values & $2,4,6,8$ \\
\hline
\end{tabular}


Table 2. Random Consistency Index

\begin{tabular}{lccccccccc}
\hline Matrix size (n) & 2 & 3 & 4 & 5 & 6 & 7 & 8 & 9 & 10 \\
\hline R.I. & 0 & 0.58 & 0.9 & 1.12 & 1.24 & 1.32 & 1.41 & 1.25 & 1.49 \\
\hline
\end{tabular}


Table 3. Fuzzy comparison scale

\begin{tabular}{ccc}
\hline Crisp & Linguistic term & Fuzzy \\
\hline 1 & Equally important & $(1,1,1)$ \\
3 & Slightly more important & $(3-\delta, 3,3+\delta)$ \\
5 & More important & $(5-\delta, 5,5+\delta)$ \\
7 & Much more important & $(7-\delta, 7,7+\delta)$ \\
9 & Absolutely more important & $(9-\delta, 9,9)$ \\
$2,4,6,8$ & Intermediate values & $(\mathrm{x}-1, \mathrm{x}, \mathrm{x}+1)$ \\
\hline
\end{tabular}


Table 4. Proposed decision-making tree

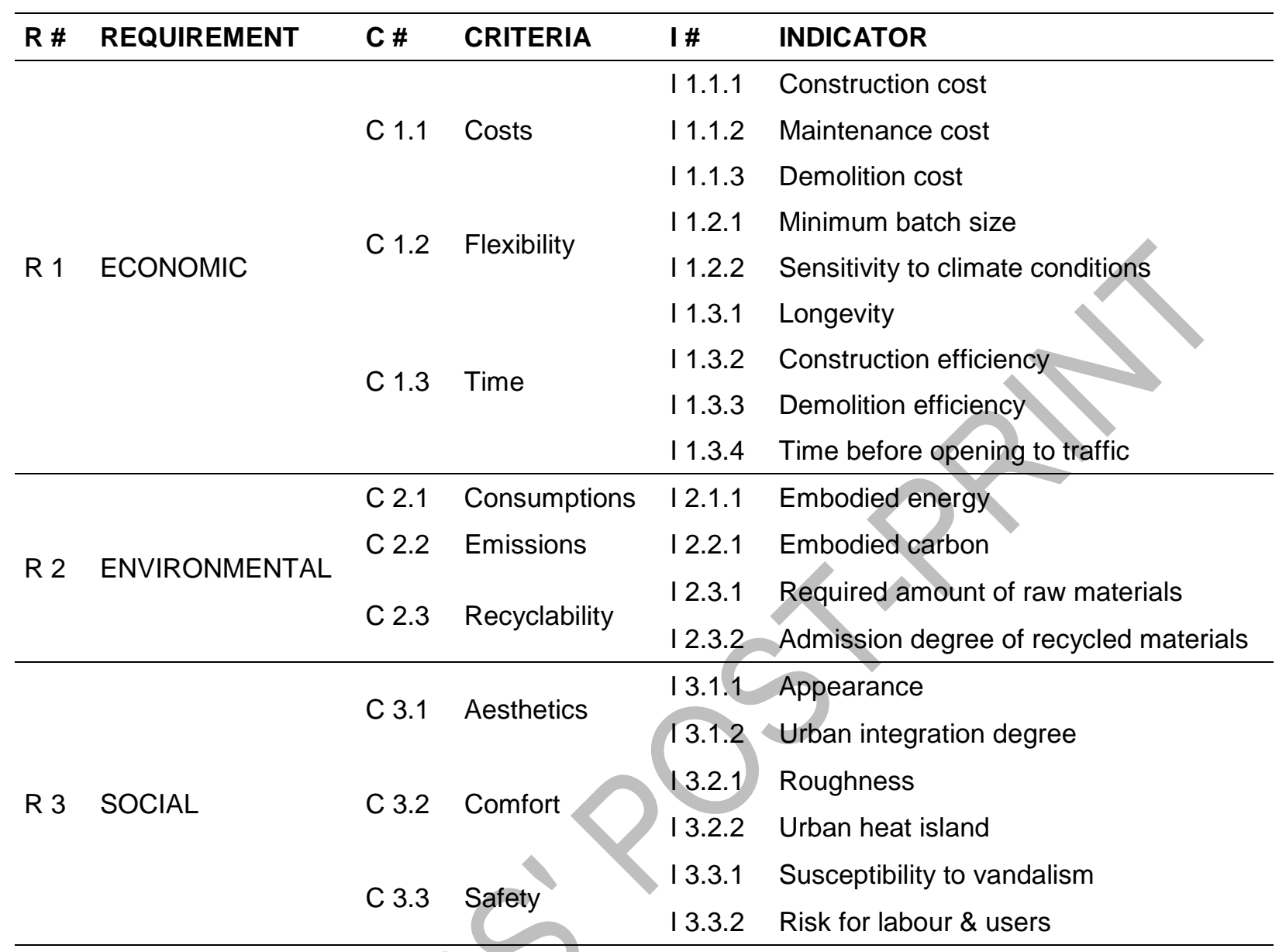


Table 5. Experts' judgments regarding each of the three decision-level

\begin{tabular}{|c|c|c|c|c|c|c|c|c|c|c|c|}
\hline \multirow{2}{*}{$\begin{array}{l}\text { Pairwise } \\
\text { comparison }\end{array}$} & \multicolumn{10}{|c|}{ Expert number } & \multirow{2}{*}{ C.R. } \\
\hline & 1 & 2 & 3 & 4 & 5 & 6 & 7 & 8 & 9 & 10 & \\
\hline R 1 vs R 2 & El- & El & El- & MI & AMI & EI & LI & El & LI & MI & \\
\hline R 1 vs R 3 & SLI- & MI & SLI- & MMI & MMI+ & El & SLI- & El & LI & $\mathrm{Ml}$ & 0.001 \\
\hline R 2 vs R 3 & SLI- & SMI & SLI & SMI & SLI & El & SMI & El & $\mathrm{El}+$ & $\mathrm{El}+$ & \\
\hline C 1.1 vs C 1.2 & SMI+ & MMI & El- & MMI & AMI & El- & LI- & $\mathrm{Ml}$ & SLI- & & \\
\hline C 1.1 vs C 1.3 & $\mathrm{Ml+}$ & $\mathrm{MMI+}$ & SLI- & $\mathrm{El}$ & Ml+ & El- & $\mathrm{El}+$ & SMI & SLI- & MI & 0.001 \\
\hline C 1.2 vs C 1.3 & $\mathrm{El}+$ & SMI & $\mathrm{LI}$ & MLI & SLI- & El- & MI & SLI & $\mathrm{El+}$ & $\mathrm{El}+$ & \\
\hline C 2.1 vs C 2.2 & $\mathrm{EI}$ & $\mathrm{LI}$ & SLI & MMI & SMI & SMI & $\mathrm{El}$ & & SLI- & $\mathrm{SI}$ & \\
\hline C 2.1 vs C 2.3 & El & SLI & LI- & SMI+ & SMI & Ml+ & El & 5 & & $\mathrm{El}+$ & 0.003 \\
\hline C 2.2 vs C 2.3 & El & SMI & $\mathrm{LI}$ & SLI- & El & MI & 2 & 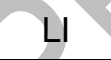 & El- & SLI- & \\
\hline C 3.1 vs C 3.2 & El- & $\mathrm{LI}$ & El- & SLI- & $\mathrm{El+}$ & El & 2 & MI & SLI & MI & \\
\hline C 3.1 vs C 3.3 & $\mathrm{LI}$ & MLI & El- & $\mathrm{MLI}$ & MI & TVILI & 1 & El & $\mathrm{LI}$ & El & 0.005 \\
\hline C 3.2 vs C 3.3 & LI & SLI & El- & SLI- & MI & MLI- & El & SLI & SLI- & LI & \\
\hline | 1.1.1 vs | 1.1.2 & El- & SLI- & El- & SMI & AMI & El- & LI- & El & SLI & SMI & \\
\hline | 1.1.1 vs | 1.1.3 & SLI- & MI & LI & MMI & $\mathrm{Ml+}$ & MMI & SMI & MMI+ & MMI & MMI & 0.015 \\
\hline | 1.1.2 vs | 1.1.3 & SLI- & $\mathrm{MMI+}$ & $\mathrm{LI}$ & $\mathrm{Ml}+$ & SLI- & $\mathrm{Ml+}$ & MMI & $\mathrm{MMI+}$ & MMI+ & $\mathrm{MI}$ & \\
\hline | 1.2.1 vs | 1.2.2 & SMI & MMI & LI- & $\mathrm{MLI}$ & $\mathrm{MLI}$ & SMI & MLI- & $\mathrm{EI}$ & MLI & $\mathrm{MI}$ & 0.000 \\
\hline I 1.3.1 vs I 1.3.2 & MI & El- & $\mathrm{El}-$ & SMI & $\mathrm{MMI}$ & $\mathrm{Ml+}$ & MLI & MI & SMI+ & $\mathrm{El}$ & \\
\hline | 1.3.1 vs | 1.3.3 & MI & MI & LI & AMI & AMI & MMI+ & SMI+ & AMI & MMI & SMI & \\
\hline | 1.3.1 vs | 1.3.4 & MI & & -5 & MI & MI & MMI & SMI & MMI & $\mathrm{Ml+}$ & SLI & 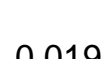 \\
\hline | 1.3.2 vs | 1.3.3 & SMI & MI & $\mathrm{El}-$ & MMI & $\mathrm{El}+$ & SMI & MMI+ & MMI & MI & SMI & 0.019 \\
\hline | 1.3.2 vs | 1.3.4 & SMI & MI & LI- & MI & $\mathrm{LI}$ & SMI+ & MI & El & SMI & El & \\
\hline | 1.3.3 vs | 1.3.4 & 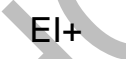 & LI & LI- & LI- & MLI- & El- & El- & LI & SLI- & SLI- & \\
\hline | 2.3.1 vs | 2.3.2 & SMI & $\mathrm{EI}$ & El- & MMI & $\mathrm{El}$ & MI & MLI- & $\mathrm{Ml+}$ & $\mathrm{El}$ & $\mathrm{EI}$ & 0.000 \\
\hline | 3.1.1 vs | 3.1.2 & SMI & El & El- & MLI & El & El- & MLI & $\mathrm{LI}$ & SLI- & El- & 0.000 \\
\hline I 3.2.1 vs I 3.2.2 & LI- & $\mathrm{Ml}$ & LI- & $\mathrm{El}$ & SMI+ & LI- & SLI- & SMI & $\mathrm{LI}$ & $\mathrm{MI}$ & 0.000 \\
\hline | 3.3.1 vs | 3.3.2 & MLI & LI & LI- & $\mathrm{LI}$ & SMI+ & El- & MMI & $\mathrm{LI}$ & MLI & MLI & 0.000 \\
\hline
\end{tabular}


Table 6. Descriptive characteristics of the set of indicators

\begin{tabular}{|c|c|c|c|c|c|c|c|c|c|c|c|}
\hline \# I & $\begin{array}{c}\text { Units of } \\
\text { measurement }\end{array}$ & Type & Nature & $X_{\min }$ & $\mathbf{X}_{\max }$ & $\mathbf{X}_{\mathrm{m} . \mathrm{I} . \mathrm{PA}}$ & $\mathbf{X}_{\mathrm{m} . \mathrm{I} . \mathrm{PC}}$ & $\mathbf{X}_{\mathrm{m} . \mathrm{IIICP}}$ & $C_{i}$ & $\mathbf{K}_{\mathbf{i}}$ & $\mathbf{P}_{\mathbf{i}}$ \\
\hline | 1.1 .1 & $€ / \mathrm{m}^{2}$ & D & $S$ & 0 & 50 & (11.48) & (22.12) & (34.13) & 15 & 0.025 & 2 \\
\hline | 1.1 .2 & $€ / \mathrm{m}^{2} / \mathrm{yr}$ & D & $S$ & 0 & 8 & $(4.94)$ & $(4.60)$ & $(2.13)$ & 3 & 0.075 & 2.5 \\
\hline | 1.1.3 & $€ / \mathrm{m}^{2}$ & D & S & 0 & 10 & $(2.65)$ & $(4.46)$ & $(5.80)$ & 3.5 & 0.025 & 2 \\
\hline I 1.2 .1 & $\mathrm{~m}^{2}$ & D & D & 0 & 50 & - & - & - & 30 & 0.01 & 5 \\
\hline | 1.2 .2 & point & 1 & D & 0 & 100 & - & - & - & 35 & 0.2 & 2 \\
\hline | 1.3.1 & years & 1 & $S$ & 0 & 40 & (17) & (23) & (27) & 15 & 0 & 1 \\
\hline | 1.3.2 & $\mathrm{h} / \mathrm{m}^{2}$ & D & $S$ & 0 & 0.75 & $(0.07)$ & $(0.10)$ & $(0.48)$ & 0.1 & 0.005 & 2 \\
\hline | 1.3.3 & $\mathrm{h} / \mathrm{m}^{2}$ & D & $S$ & 0 & 0.25 & $(0.088)$ & $(0.101)$ & $(0.164)$ & 0.075 & 0.005 & 2 \\
\hline I 1.3.4 & hours & D & D & 0 & 200 & - & - & & 150 & 0.001 & 6 \\
\hline | 2.1 .1 & $\mathrm{MJ} / \mathrm{m}^{2}$ & D & D & 0 & 1000 & - & - & & 300 & 0.1 & 2 \\
\hline | 2.2.1 & $\mathrm{kgCO}_{2} / \mathrm{m}^{2}$ & D & D & 0 & 50 & - & . & & 35 & 0.9 & 0.75 \\
\hline | 2.3.1 & $\mathrm{kg} / \mathrm{m}^{2}$ & D & D & 0 & 1000 & - & & & 300 & 0.2 & 4 \\
\hline | 2.3.2 & $\%$ & 1 & D & 0 & 50 & & & & 15 & 0,15 & 3 \\
\hline | 3.1 .1 & point & 1 & D & 0 & 75 & & & - & 20 & 0.5 & 1 \\
\hline | 3.1.2 & point & 1 & D & 0 & 100 & & & - & 40 & 0.2 & 4 \\
\hline | 3.2.1 & point & 1 & D & 0 & 100 & & - & - & 35 & 0.25 & 1 \\
\hline | 3.2.2 & Albedo & 1 & $S$ & 0 & 1 & (0.05 & (0.30) & $(0.35)$ & 0.15 & 0.1 & 3.5 \\
\hline | 3.3.1 & point & D & D & 0 & 100 & & - & - & 25 & 0.025 & 2 \\
\hline | 3.3.2 & point & D & D & 0 & 100 & - & - & - & 40 & 0.2 & 3 \\
\hline
\end{tabular}

